Rill, R. L., Hilliard, P. R., \& Levy, G. C. (1983) J. Biol. Chem. 258, 250-256.

Robinson, C. (1961) Tetrahedron 13, 219-234.

Rupprecht, A., \& Forslind, B. (1970) Biochim. Biophys. Acta 204, 304-316.

Samulski, E. T., \& Luz, Z. (1980) J. Chem. Phys. 73, 142-147.

Senechal, E., Maret, G., \& Dransfeld, K. (1980) Int. J. Biol. Macromol. 2, 256-262.
Tanford, C. (1961) in Physical Chemistry of Macromolecules, Wiley, New York.

Trohalaki, S., Brian, A. A., Frisch, H. L., \& Lerman, L. S. (1984) Biophys. J. 45, 777-782.

Vold, R. R., Brandes, R., Tsang, P., Kearns, D. R., Vold, R. L., \& Rupprecht, A. (1986) J. Am. Chem. Soc. 108, 302-303.

Waldenstein, P., Rabidean, S. W., \& Jackson, J. A. (1964) J. Chem. Phys. 41, 3407-3411.

\title{
Thermostability of Double-Stranded Deoxyribonucleic Acids: Effects of Covalent Additions of a Psoralen ${ }^{\dagger}$
}

\author{
Yun-bo Shi and John E. Hearst* \\ Department of Chemistry, University of California, Berkeley, Berkeley, California 94720 \\ Received April 25, 1986; Revised Manuscript Received June 24, 1986
}

\begin{abstract}
We have carried out a thermodynamic study on the effects of covalent additions of the psoralen derivative HMT, 4'-(hydroxymethyl)-4,5',8-trimethylpsoralen, on the stability of double-stranded deoxyoligonucleotides. This was done with two systems. The first was a double-stranded DNA formed by two non-self-complementary oligonucleotides, 5'-GAAGCTACGAGC-3' and 5'-GCTCGTAGCTTC-3', where we site specifically placed an HMT molecule on the thymidine residue in oligonucleotide 5'-GAAGCTACGAGC-3' as either a furan-side monoadduct or a pyrone-side monoadduct. The second was a double-stranded DNA formed by a self-complementary oligonucleotide, 5'-GGGTACCC-3', where we placed an HMT molecule on the thymidine residue of each strand as a furan-side monoadduct or cross-linked the two strands with an HMT molecule linked to the two thymidines. We found that HMT cross-linking of the two strands stabilizes the double helix formed by $5^{\prime}$-GGGTACCC-3', as one might expect. Less predictable results were that the monoaddition of a psoralen stabilizes the double helix formed by the two non-self-complementary oligonucleotides by as much as $1.3 \mathrm{kcal} / \mathrm{mol}$ as a furan-side monoadduct and 0.7 $\mathrm{kcal} / \mathrm{mol}$ as a pyrone-side monoadduct at $25^{\circ} \mathrm{C}$ in $50 \mathrm{mM} \mathrm{NaCl}$. In contrast, the monoaddition of a psoralen on each of the two thymidines in the double helix formed by $5^{\prime}$-GGGTACCC-3' destabilizes the helix by $1.8 \mathrm{kcal} / \mathrm{mol}$ at $25^{\circ} \mathrm{C}$ in $1 \mathrm{M} \mathrm{NaCl}$. This destabilization arises from an unfavorable enthalpy change $(8.6$ $\mathrm{kcal} / \mathrm{mol})$ and a favorable entropy change $(23 \mathrm{cal} / \mathrm{K} \cdot \mathrm{mol})$ due to the two HMT molecules at the centers of each strand. The measured hypochromicity on helix formation also suggests a substantial perturbation in stacking interactions when one HMT is added to each of the two thymidines in the double helix.
\end{abstract}

B double-stranded nucleic acids, psoralens (furocoumarins) have been widely used as biochemical probes of nucleic acid structure [for reviews, see Song and Tapley (1979) and Cimino et al. (1985)] and as drugs in the treatment of skin diseases (Fitzpatrick et al., 1982; Parrish et al., 1982). The chemistry of psoralen-nucleic acid intractions is well understood (Song \& Tapley, 1979; Cimino et al., 1985; Parsons, 1980). The initial step is the intercalation of psoralen molecules between base pairs in a double-stranded nucleic acid helix. Upon UV irradiation $(320-400 \mathrm{~nm}$ ) the intercalated psoralens can react with pyrimidine bases through cyclobutane addition to produce psoralen-pyrimidine monoadducts. Due to the bifunctional nature of psoralens, two kinds of monoadducts are formed: the furan-side monoadduct, $\mathrm{M}_{\mathrm{Fu}}{ }^{1}$, which is formed through the cycloaddition between the $4^{\prime}, 5^{\prime}$ double bond of a psoralen and the 5,6 double bond of a pyrimidine base, and the pyrone-side monoadduct, $\mathbf{M}_{\mathrm{Py}}$, which is formed through the cycloaddition

${ }^{\dagger}$ This work was supported by NIH Grant GM 11180.

* Author to whom correspondence should be addressed. between the 3,4 double bond of a psoralen and the 5,6 double bond of a pyrimidine base. By absorbing a second photon, the furan-side monoadduct can be converted to a diadduct when it is located at a cross-linkable site, i.e., when there is an adjacent pyrimidine base located on the other strand for the photoreaction. The pyrone-side monoadduct does not absorb photons above $320 \mathrm{~nm}$, so it cannot be converted to a diadduct at wavelengths between 320 and $400 \mathrm{~nm}$. The structures of the adducts formed between thymidine and several psoralen derivatives have been determined by techniques such as mass spectroscopy, proton NMR, and X-ray crystallography (Straub et al., 1982; Kanne et al., 1982a,b; Peckler et al., 1982).

\footnotetext{
${ }^{1}$ Abbreviations: HMT, 4'-(hydroxymethyl)-4,5',8-trimethylpsoralen; EtOH, ethanol; ATP, adenosine 5'-triphosphate; Tris, tris(hydroxymethyl)aminomethane; EDTA, ethylenediaminetetraacetic acid; $\mathrm{M}_{\mathrm{Fu}}$, furan-side monoadduct; $M_{P y}$, pyrone-side monoadduct; $5^{\prime}-[T$ $\left.(\mathrm{HMT})_{\mathrm{Fu}}\right]-3^{\prime}$, thymidine-HMT furan-side monoadduct with HMT on $3^{\prime}$-side of thymidine; $5^{\prime}$ - $\left[\mathrm{T}(\mathrm{HMT})_{\mathrm{Py}}\right]-3^{\prime}$, thymidine-HMT pyrone-side monoadduct with HMT on $3^{\prime}$-side of thymidine; T-HMT-T, thymidineHMT-thymidine diadduct; T-HMT-C, thymidine-HMT-cytidine diadduct; C-HMT-C, cytidine-HMT-cytidine diadduct.
} 
Double-stranded nucleic acid intercalators, such as ethidium and proflavin, stabilize the double helix through favorable stacking interactions with adjacent bases upon intercalation. The intercalation is associated with a favorable enthalpy change and an unfavorable entropy change (Nelson \& Tinoco, 1984; Baba et al., 1981). Similarly, the intercalation of a psoralen into a double-stranded nucleic acid also provides a favorable $\Delta H^{\circ}$ and an unfavorable $\Delta S^{\circ}$, resulting a net stabilization of the helix (Kao, 1984). However, the effects of covalent additions of a psoralen on the thermostability of double-stranded nucleic acids are essentially unknown. In this paper, we present a thermodynamic study of the effects of several well-defined adducts of the psoralen derivative HMT (4'-hydroxymethyl-4,5',8-trimethylpsoralen) on the stability of two double-stranded DNA oligonucleotides. HMT was used in this study because (1) HMT and its pyrimidine adducts are neutral, and therefore do not have the added complications associated with charged intercalators, (2) the adducts are well characterized, and (3) the different HMT-adducted oligonucleotides can be resolved by a polyacrylamide gel system.

Our results showed that (1) monoaddition of HMT does not destabilize the double-stranded DNA but stabilizes the helix to some extent, (2) HMT cross-linking of the two strands of a double-stranded DNA, as expected, remarkably stabilizes the double helix, and (3) the double-stranded helix formed by a self-complementary oligonucleotide containing in the center a thymidine-HMT furan-side monoadduct is, however, dramatically destabilized compared to the unmodified doublestranded helix.

\section{Materials ANd Methods}

Materials. HMT and $\left[{ }^{3} \mathrm{H}\right] \mathrm{HMT}$ were gifts from HRI Associates Inc. (Berkeley, CA). All oligonucleotides were synthesized on an automated DNA synthesizer by the phosphotriester method (SAM ONE DNA synthesizer, Biosearch). After synthesis, the oligonucleotides were deprotected and purified by electrophoresis on a $20 \%$ polyacrylamide- $7 \mathrm{M}$ urea gel followed by EtOH precipitation. $\left[\gamma-{ }^{32} \mathrm{P}\right] \mathrm{ATP}$ and T4 polynucleotide kinase were obtained from Amersham. DNase II, bovine intestine alkaline phosphatase, and phosphodiesterase II were obtained from Sigma.

5'-End Labeling of DNA Oligonucleotides. The oligonucleotides were 5 '-end labeled with $\left[\gamma^{-32} \mathrm{P}\right] \mathrm{ATP}$ and T4 polynucleotide kinase according to standard procedures (Maniatis et al., 1982). The amount of enzyme in each aliquot used in the following experiments was approximately equal to the amount required to completely phosphorylate the $5^{\prime}$-end of the oligonucleotide, which was estimated on the basis of the amount of DNA present, the incubation time (usually 2-5 h), and the assumption that 1 unit of enzyme will kinase $1 \mathrm{nmol}$ of oligonucleotide in $0.5 \mathrm{~h}$ at $37^{\circ} \mathrm{C}$. A $1 \times$ linker kinase buffer (70 mM Tris- $\mathrm{HCl}, 10 \mathrm{mM} \mathrm{MgCl}, 5 \mathrm{mM}$ dithiothreitol, $\mathrm{pH}$ 7.6) containing the oligonucleotide to be labeled, $\left[\gamma^{32} \mathrm{P}\right] \mathrm{ATP}$, and an aliquot of kinase was incubated at $37^{\circ} \mathrm{C}$ for a few hours. The reaction was then chased by adding cold ATP to a final concentration of $1 \mathrm{mM}$, another aliquot of enzyme, $10 \times$ linker kinase buffer to maintain a $1 \times$ buffer concentration and incubating at $37^{\circ} \mathrm{C}$. To ensure complete kinasing, a third aliquot of kinase was added, and the solution was incubated again at $37^{\circ} \mathrm{C}$. The mixture either was used directly or was EtOH-precipitated (10 $\mathrm{mM} \mathrm{MgCl}_{2}, 0.2 \mathrm{M} \mathrm{NaCl}, 2.5 \mathrm{v} / \mathrm{v}$ EtOH). After EtOH precipitation, the DNA was then dissolved in water or the appropriate buffer and stored at -20 ${ }^{\circ} \mathrm{C}$.

Preparation of HMT-Cross-Linked Double-Stranded 5'. $G G G T A C C C-3^{\prime}$. The cross-link was prepared following the procedures of Cimino et al. (1986). A total of $400 \mu \mathrm{g}$ of $5^{\prime}$-GGGTACCC-3' was dissolved in $700 \mathrm{~mL}$ of irradiation buffer ( $50 \mathrm{mM}$ Tris- $\mathrm{HCl}, 0.1 \mathrm{mM}$ EDTA, $150 \mathrm{mM} \mathrm{NaCl}, 10$ $\mathrm{mM} \mathrm{MgCl}, \mathrm{pH} 7.6$ ) after kinasing and EtOH precipitation. The solution was split into two 1.5-mL Eppendorf tubes, each containing $350 \mu \mathrm{l}$, and $15 \mu \mathrm{L}$ of concentrated HMT/EtOH solution was added to each tube (final HMT concentration was $1.5 \times 10^{-4} \mathrm{M}$ ). Each mixture was irradiated for $3 \mathrm{~min}$ at $4{ }^{\circ} \mathrm{C}$ with broad-band light from a $2.5-\mathrm{kW} \mathrm{Hg} / \mathrm{Xe}$ lamp, which was filtered through Pyrex glass and an aqueous cobaltous nitrate solution $\left[1.7 \% \mathrm{Co}\left(\mathrm{NO}_{3}\right)_{2}, 2 \% \mathrm{NaCl}, 9-\mathrm{cm}\right.$ path length] (320-380 nm, $1 \mathrm{~W} / \mathrm{cm}^{2}$; Cimino et al., 1986). The HMT addition and subsequent irradiation were repeated 3 times for each tube. Unreacted and photodamaged HMT were removed by chloroform and ether extractions. The irradiated DNA was EtOH-precipitated and electrophoresed on a $20 \%$ polyacrylamide-7 M urea gel $(40 \mathrm{~cm} \times 40 \mathrm{~cm} \times 0.05 \mathrm{~cm}, 35$ $\mathrm{W}$ for $3-4 \mathrm{~h}$ ). The cross-link and the unmodified DNA bands were located by autoradiography, excised, and eluted from the gel with a solution of $50 \mathrm{mM} \mathrm{NaCl}-1 \mathrm{mM}$ EDTA. The unmodified DNA and cross-link were finally EtOH precipitated, washed, and dissolved each in $200 \mu \mathrm{L}$ of $\mathrm{H}_{2} \mathrm{O}$. The unmodified DNA was stored at $-20^{\circ} \mathrm{C}$ and the cross-link at $4^{\circ} \mathrm{C}$.

Preparation of HMT Furan-Side Monoadducted 5'GGGTACCC-3'. About $140 \mu \mathrm{g}$ of the cross-link prepared as above was dissolved in $9 \mathrm{~mL}$ of $\mathrm{H}_{2} \mathrm{O}$. The cross-link solution was photoreversed with $297-\mathrm{nm}$ monochromatic light in $3-\mathrm{mL}$ aliquots. Under these conditions, the photoreversal produces a 4:1 ratio of the furan-side monoadducted oligonucleotide to the pyrone-side counterpart (Cinimo et al., 1986). Each aliquot was irradiated for $65 \mathrm{~min}$ at a light intensity of $7 \times 10^{14}$ photons/s [determined by actinometry with $\mathrm{K}_{3} \mathrm{Fe}\left(\mathrm{C}_{2} \mathrm{O}_{4}\right)_{3}$ ], vacuum dried in a Speedvac concentrator (Savant Instrument Inc.) without heating, and electrophoresed on a $20 \%$ polyacrylamide-7 $\mathrm{M}$ urea gel. The unmodified and furan-side monoadducted DNA bands and the cross-link band were isolated as described above, $\mathrm{EtOH}$-precipitated, washed, and dissolved in water. About $35 \mu \mathrm{g}$ of furan-side monoadducted $5^{\prime}$-GGGTACCC-3' was obtained. The unmodified DNA was frozen, and the cross-link and the monoadducted DNA were refrigerated.

Preparation of HMT-Monoadducted 5'-GAAGCT$A C G A G C-3$ '. In order to make the desired monoadducted oligonucleotides, the HMT cross-link between 5'-GAAGCTACGAGC- $3^{\prime}$ and $5^{\prime}$-TCGTAGCT-3' through the middle thymidines on each oligonucleotide were prepared first. It is known that in this system many side products are generated, especially after repeated HMT addition and subsequent irradiation (M. Gartenberg, G. D. Cimino, Y.-B. Shi, and J. E. Hearst, unpublished results). Therefore, the HMT concentration was lowered and the irradiation was repeated only twice instead of 3 times as in the procedure used for the generation of the HMT cross-link of 5'-GGGTACCC-3'. A total of $480 \mu \mathrm{L}$ of kinasing mixture containing $500 \mu \mathrm{g}$ of kinased oligonucleotide 5'-GAAGCTACGAGC-3' was adjusted to $150 \mathrm{mM} \mathrm{NaCl}$ and $10 \mathrm{mM} \mathrm{MgCl}$. This solution was mixed with $1000 \mu \mathrm{L}$ of irradiation buffer containing 400 $\mu \mathrm{g}$ of unkinased $5^{\prime}$-TCGTAGCT-3' and then split equally into four 1.5-mL Eppendorf tubes. HMT/EtOH stock solution was added to each tube to a final concentration of $1.2 \times 10^{-4}$ M HMT, and the mixture was irradiated with broad-band light $(320-380 \mathrm{~nm})$ for $3 \mathrm{~min}$ at $4{ }^{\circ} \mathrm{C}$. The HMT addition and subsequent irradiation were repeated once. The unreacted and UV-damaged HMT were removed by chloroform and 
ether extractions. The DNA was then EtOH precipitated and electrophoresed on a $20 \%$ polyacrylamide- $7 \mathrm{M}$ urea gel. It was found that during this procedure the oligonucleotide $5^{\prime}$ TCGTAGCT $-3^{\prime}$ was partially 5'-phosphorylated by the enzyme and ATP in the reaction mixture. A kinased DNA runs differently from its unkinased counterpart on a polyacrylamide gel because of the extra negative charge. Therefore, the two cross-links (either the furan end or the pyrone end attached to 5'-GAAGCTACGAGC-3', see Identification of HMTDNA Adducts under Results) were not resolved on the gel. Instead, a single broad band, which contained the two crosslinks with either kinased or unkinased 5'-TCGTAGCT-3' was obtained. The cross-links and unmodified oligonucleotides were isolated and purified as described above.

The cross-links were photoreversed in order to generate the HMT-monoadducted oligonucleotide 5'-GAAGCTACGAGC-3'. About $200 \mu \mathrm{g}$ of the cross-links was dissolved in $6 \mathrm{~mL}$ of $\mathrm{H}_{2} \mathrm{O}$ and photoreversed in a Pyrex dish (1-in. diameter) covered with Reynolds Film 910 to cut off light below $240 \mathrm{~nm}$. The dish was placed $2.5 \mathrm{in}$. below a lowpressure 40-W germicidal lamp with an intensity of about 1.5 $\mathrm{mW} / \mathrm{cm}^{2}$ (estimated with a black-ray ultraviolet meter, Model J-225, short UV meter, Ultra-violet Products, Inc., San Gabriel, CA). The solution was divided into three $2-\mathrm{mL}$ aliquots. Each aliquot was added to the dish and irradiated for $2.5 \mathrm{~min}$ with continuous stirring. After photoreversal, the adducts were vacuum-dried in a Speedvac concentrator and purified by gel electrophoresis. The furan-side and pyrone-side monoadducted oligonucleotide 5'-GAAGCTACGAGC-3' (about 30 and 15 $\mu \mathrm{g}$, respectively) and the unmodified oligonucleotide $5^{\prime} \cdot \mathrm{GA}$ AGCTACGAGC-3' were subjected to a second EtOH precipitation, washed with $70 \% \mathrm{EtOH}$, and finally dissolved in $\mathrm{H}_{2} \mathrm{O}$ and kept refrigerated.

Concentration Measurement. The extinction coefficients per mole of single-stranded oligonucleotide at $260 \mathrm{~nm}, 25^{\circ} \mathrm{C}$, and neutral $\mathrm{pH}$ were calculated from the extinction coefficients of mononucleotide and dinucleotide phosphates (Fasman, 1975). The values for 5'-GGGTACCC-3', 5'-GAAGCTACGAGC-3', and its complement $5^{\prime}$-GCTCGTAGCTTC-3' are $7.5 \times 10^{4}, 12 \times 10^{4}$, and $11 \times 10^{4} \mathrm{M}^{-1} \mathrm{~cm}^{-1}$, respectively. The specific activities ( $5^{\prime}$-end labeled ${ }^{32} \mathrm{P}$ counts per minute per mole of single-stranded oligonucleotide, typically $10^{14}$ $\mathrm{cpm} / \mathrm{mol}$ ) for these oligonucleotides were thus measured on the basis of the absorption at $260 \mathrm{~nm}$, the extinction coefficients above, and ${ }^{32} \mathrm{P}$ Cerenkov counting. (The extinction coefficients of the furan-side monoadducted and pyrone-side monoadducted 5'-GAAGCTACGAGC-3' are both equal to $13 \times 10^{4} \mathrm{M}^{-1} \mathrm{~cm}^{-1}$ as determined on the basis of the specific activity and the absorption of the HMT-modified oligonucleotides). The concentrations of the oligonucleotide(s) and the psoralen-modified derivative(s) could then be determined by ${ }^{32} \mathrm{P}$ Cerenkov counting.

Melting Curve Measurement and Data Analysis. Melting curves were obtained on a Gilford Model 250 UV-vis spectrophotometer with a Gilford Model 2527 thermoprogrammer as described earlier (Aboul-ela et al., 1985; Borer et al., 1974). The buffer used for the melting curves of double-stranded 5'-GGGTACCC-3' and its HMT-modified derivatives was 1 $\mathrm{M} \mathrm{NaCl}, 10 \mathrm{mM}$ phosphate, and $1 \mathrm{mM}$ EDTA in $\mathrm{H}_{2} \mathrm{O}$ at $\mathrm{pH}$ 7.0, unless otherwise indicated. The buffer used for melting curves of double-stranded DNA formed by unmodified or monoadducted 5'-GAAGCTACGAGC- $3^{\prime}$ and its complement was $50 \mathrm{mM} \mathrm{NaCl}, 10 \mathrm{mM}$ phosphate, and $2 \mathrm{mM}$ EDTA at pH 7.0 because of the high stability of the double-stranded DNA helices formed in this system. The rate of temperature

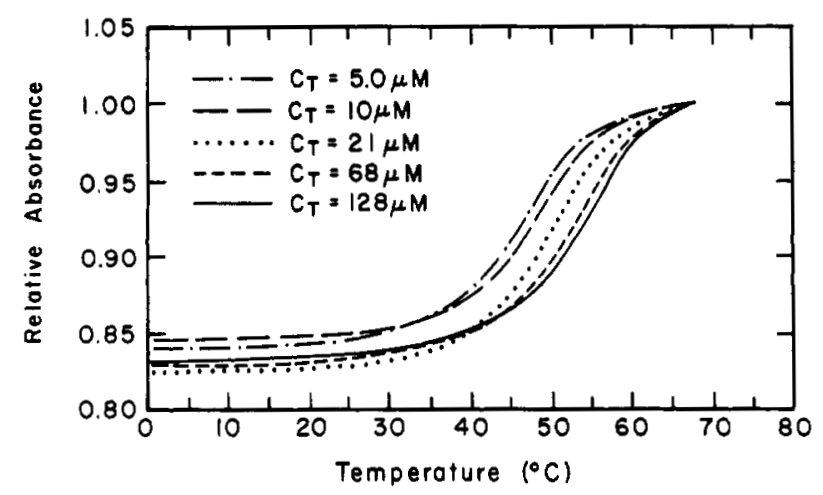

FIGURE 1: Melting curves of double-stranded DNA formed by 5 GAAGC [T(HMT) $\left.)_{\mathrm{Py}}\right]$ ACGAGC-3' and 5'-GCTCGTAGCTTC-3' at different total strand concentrations $\left(C_{\mathrm{T}}\right)$ in $50 \mathrm{mM} \mathrm{NaCl}, 10$ $\mathrm{Na}_{2} \mathrm{HPO}_{4}$, and $2 \mathrm{mM}$ EDTA, $\mathrm{pH}$ 7.0. The absorptions were normalized at $67^{\circ} \mathrm{C}$. The data above $68^{\circ} \mathrm{C}$ were cut off by the plotting program. The base-line slopes for determination of melting temperatures were, however, deduced from the complete melting curves, which extended up to $75^{\circ} \mathrm{C}$.

increase was $1^{\circ} \mathrm{C} / \mathrm{min}$. Thus, the melting curves were measured at essentially equilibrium conditions, since the relaxation times of the double-stranded vs. single-stranded oligonucleotide equilibria at our conditions are much smaller than $1 \mathrm{~s}$ as estimated on the basis of kinetic data of oligonucleotides (Riesner \& Romer, 1973; Craig et al., 1971; Porschke \& Eigen, 1971).

The data were analyzed by the van't Hoff method to obtain thermodynamic parameters for double-stranded DNA formation (Martin et al., 1971; Aboul-ela et al., 1985). The melting curves (for example, see Figure 1) were analyzed on the basis of a two-state model to obtain the melting temperature (the temperature at which $50 \%$ of the strands are single-stranded). The equilibrium constant for the doublestranded helix formation by a self-complementary oligonucleotide is

$$
K=\frac{f}{2(1-f)^{2} C_{\mathrm{T}}}
$$

where $C_{\mathrm{T}}$ is the total strand concentration $(\mathrm{mol} / \mathrm{L}$ or $\mathrm{M}$ ) and $f$ is the fraction of strands in double-stranded state. The values of $f$ were obtained by using the method described by Aboul-ela et al. (1985). Since the equilibrium constant is related to the thermodynamic parameters $\Delta H^{\circ}, \Delta S^{\circ}$, and $\Delta G^{\circ}$ through the equation

$$
\Delta G^{\circ}=-R T \ln K=\Delta H^{\circ}-T \Delta S^{\circ}
$$

the following equations can be derived at the melting temperature, $T_{\mathrm{m}}$, at with $f=1 / 2$ :

$$
\begin{gathered}
\ln C_{\mathrm{T}}=\Delta H^{\circ} /\left(R T_{\mathrm{m}}\right)-\Delta S^{\circ} / R \\
\Delta G^{\circ}\left(T_{\mathrm{m}}\right)=R T_{\mathrm{m}} \ln C_{\mathrm{T}}
\end{gathered}
$$

The formulas corresponding to (1), (3), and (4) for double-stranded DNA formation from non-self-complementary oligonucleotides are respectively (5), (6), and (7) [see Aboul-ela et al. (1985)]:

$$
\begin{gathered}
K=\frac{2 f}{2(1-f)^{2} C_{\mathrm{T}}} \\
\ln \left(C_{\mathrm{T}} / 4\right)=\Delta H^{\circ} /\left(R T_{\mathrm{m}}\right)-\Delta S^{\circ} / R \\
\Delta G^{\circ}\left(T_{\mathrm{m}}\right)=R T_{\mathrm{m}} \ln \left(C_{\mathrm{T}} / 4\right)
\end{gathered}
$$

Hypochromicity or diminution of absorbance at $260 \mathrm{~nm}$ for double-stranded DNA formation is caused by stacking interactions between base pairs. It is temperature-dependent 


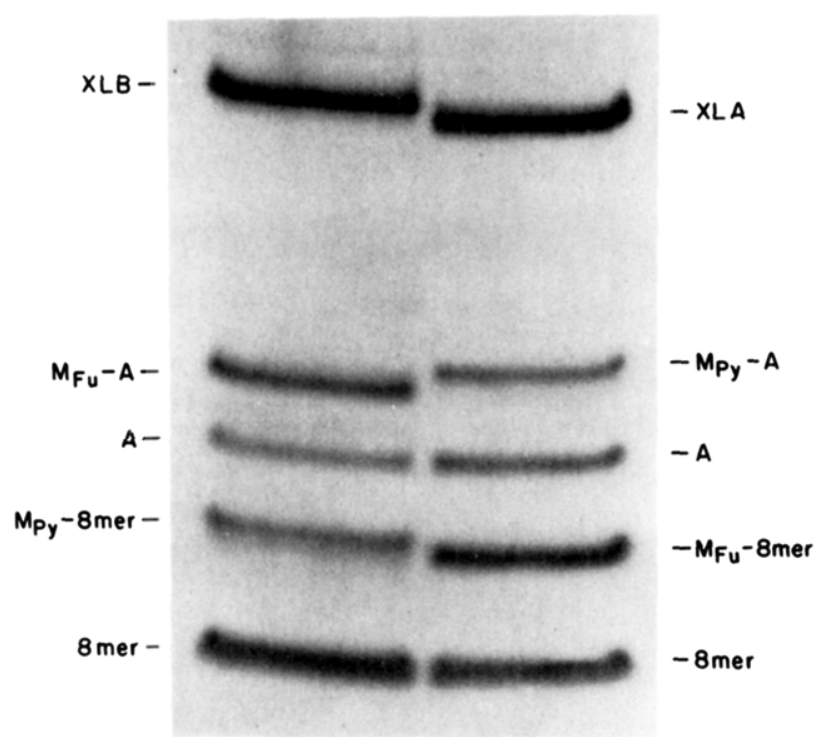

FIGURE 2: Isolation and characterization of HMT-oligonucleotide photoadducts by $20 \%$ polyacrylamide $-7 \mathrm{M}$ urea gel electrophoresis. XLA and XLB were purified on a $20 \%$ polyacrylamide $-7 \mathrm{M}$ urea gel and then photoreversed as described in the text before being applied to this gel. Abbreviations: 8mer, 5'-TCGTAGCT-3'; $\mathrm{M}_{\mathrm{Fu}}-8 \mathrm{mer}$, $5^{\prime}$-TCG $\left.[\text { T(HMT) })_{\mathrm{Fu}}\right]$ AGCT-3'; $\mathrm{M}_{\mathrm{Py}}-8 \mathrm{mer}, 5^{\prime}$-TCG $\left[\mathrm{T}(\mathrm{HMT})_{\mathrm{Py}}\right]-$ AGCT-3'; A, 5'-GAAGCTACGAGC-3'; $\mathrm{M}_{\mathrm{Fu}}-\mathrm{A}, 5^{\prime}$-GAAGC[T$\left.(\mathrm{HMT})_{\mathrm{Fu}}\right]$ ACGAGC-3'; $\mathrm{M}_{\mathrm{Py}}-\mathrm{A}, 5^{\prime}-\mathrm{GAAGC}\left[\mathrm{T}(\mathrm{HMT})_{\mathrm{Py}}\right]$ ACGAGC-3'; XLA and XLB, HMT-cross-linked molecules each containing one molecule of the 8 mer and one molecule of $\mathrm{A}$.

because the temperature dependence of the absorptions of the single-stranded and double-stranded DNA are different. We therefore chose $50^{\circ} \mathrm{C}$ as a standard temperature to calculate the hypochromicity since it is around the $T_{\mathrm{m}}$ of most of the oligonucleotides studied here. The hypochromicity was calculated with the following formula as described (Martin et al., 1971):

$$
\% H=100 \frac{A_{\mathrm{s}}\left(50^{\circ} \mathrm{C}\right)-A_{\mathrm{d}}\left(50^{\circ} \mathrm{C}\right)}{A_{\mathrm{s}}\left(50^{\circ} \mathrm{C}\right)}
$$

where $\% H$ is the percent hypochromicity and $A_{\mathrm{s}}\left(50^{\circ} \mathrm{C}\right)$ and $A_{\mathrm{d}}\left(50^{\circ} \mathrm{C}\right)$ are the absorbances of the single-stranded and double-stranded species at $50^{\circ} \mathrm{C}$, respectively, which were obtained by extrapolating the absorbances from the temperature region in which all the strands are single-stranded or double-stranded to $50^{\circ} \mathrm{C}$.

\section{RESULTS}

Identification of $H M T-D N A$ Adducts. There are three types of HMT cross-linking sites in the double-stranded DNA formed between oligonucleotides 5'-GAAGCTACGAGC-3' and $5^{\prime}$-TCGTAGCT-3'. These are T-HMT-T, C-HMT-C, and T-HMT-C. Within each type of cross-link, there are two possible orientations of HMT with respect to the oligonucleotide 5'-GAAGCTACGAGC-3', i.e., with the attachment of either the furan-end or the pyrone-end of the HMT. In order to identify the cross-linking site, tritium-labeled HMTDNA cross-links were prepared essentially as described above. In this preparation, however, both oligonucleotides were $5^{\prime}$-end labeled with ${ }^{32} \mathrm{P}$. After initial cross-linking and gel electrophoresis, two intense cross-link bands (XLA and XLB) were seen in the autoradiogram. The two cross-links were isolated and purified. They were then photoreversed by exposure to 254-nm light from a low-pressure germicidal lamp and electrophoresed on a $20 \%$ polyacrylamide $-7 \mathrm{M}$ urea gel. The autoradiogram of the gel is shown in Figure 2. It is seen that a different pair of monoadducted oligonucleotides was pro- duced from each of the two cross-links (XLA and XLB). The cross-links and monoadducted oligonucleotides were isolated and purified. They were then digested sequentially with DNase II, phosphodiesterase II, and alkaline phophatase (Kanne et al., 1982a), and the digests were analyzed by HPLC (Cimino et al., 1986). The HPLC results of the two cross-links showed that both XLA and XLB contain T-HMT-T diadducts. (Monoadducts, which were probably generated during the digestion, accounted for $5-15 \%$ of the ${ }^{3} \mathrm{H}$.) Since there is only one possible T-HMT-T cross-linking site in the double-stranded DNA formed by the two oligonucleotides, XLA and XLB are HMT-DNA cross-links formed through the middle thymidine on each oligonucleotide. Similarly, it was shown that $\mathrm{M}_{\mathrm{Fu}}-\mathbf{A}$ and $\mathrm{M}_{\mathrm{Fu}}-8$ mer (see Figure 2) are furanside monoadducted oligonucleotide 5'-GAAGCTACGAGC-3' and furan-side monoadducted oligonucleotide $5^{\prime}$ TCGTAGCT-3', respectively, with the HMT attached to the middle thymidine of each oligonucleotide and that $\mathrm{M}_{\mathrm{Py}}-\mathrm{A}$ and $\mathbf{M}_{\mathrm{Py}}-8$ mer are the pyrone-side monoadducted counterparts. Thus, in XLA HMT is attached to oligonucleotide $5^{\prime}-\mathrm{GA}$ AGCTACGAGC $-3^{\prime}$ through its pyrone end, and in XLB it is attached through its furan end. $\mathrm{M}_{\mathrm{Fu}}-\mathrm{A}$ and $\mathrm{M}_{\mathrm{Py}}-\mathrm{A}$ can be then represented as $5^{\prime}$-GAAGC[T(HMT) $\left.)_{\mathrm{Fu}}\right] \mathrm{ACGAGC-3^{ \prime }}$ and 5'-GAAGC $[\text { T(HMT) })_{\text {Py }}$ ]ACGAGC-3-m, respectively. The HMT molecules in each case is at the $3^{\prime}$-side of the thymidine.

The HMT cross-linking site in the $5^{\prime}$-GGGTACCC- $3^{\prime}$ cross-link is the thymidine base on each strand (Gamper et al., 1984; Cimino et al., 1986). The site of HMT monoaddition in the furan-side monoadducted $5^{\prime}$-GGGTACCC- $3^{\prime}$ is the thymidine base of the DNA strand since it is generated from the photoreversal of the cross-link. Therefore, this monoadducted oligonucleotide can be represented as $5^{\prime}$-GGG[T(HMT) $)_{\text {Fu }}$ ACCC-3', and the HMT molecule is at the $3^{\prime}$-side of the thymidine.

Stability of HMT Adducts. It is known that both crosslinks and monoadducted oligonucleotides are photoreversible (Cimino et al., 1985; 1986; Y.-B. Shi and J. E. Hearst, unpublished results). Therefore, it is important to know whether the HMT adducts are photoreversed during the UV melting curve measurements (at $260 \mathrm{~nm}$ ). To investigate this, the oligonucleotides were recovered by EtOH precipitation after melting curve measurements and then analyzed by gel electrophoresis. The results are shown in Figure 3. It is seen that the unmodified oligonucleotide $5^{\prime}$-GAAGCTACGAGC- $3^{\prime}$ is separated from its complement $5^{\prime}$-GCTCGTAGCTTC- $3^{\prime}$ on this gel (compare lanes 2-4). Therefore, any photoreversal could be monitored by the appearance of an unmodified oligonucleotide $5^{\prime}$-GAAGCTACGAGC- $3^{\prime}$ band in the mixture of HMT-monoadducted 5'-GAAGCTACGAGC-3' and its unmodified complement. The results showed no detectable photoreversal of the monoadducted oligonucleotides occurred during the melting curve measurements (see lanes 2 and 3). Similarly, it was shown that the cross-linked and furan-side monoadducted 5'-GGGTACCC-3' are photochemically stable under the conditions used for the melting curve measurement (data not shown). These data also show that these adducts are thermally stable under these conditions.

Thermostability of Double-Stranded DNA Formed from Oligonucleotide 5'-GCTCGTAGCTTC-3' and Unmodified or HMT-Monoadducted Oligonucleotide 5'-GAAGCT$A C G A G C-3^{\prime}$. The effects of HMT monoaddition on the thermostability of double-stranded oligonucleotides were investigated by studying the melting properties of the helices formed between oligonucleotide 5'-GCTCGTAGCTTC-3' and unmodified or HMT-monoadducted oligonucleotide 5 '-GA- 


\begin{tabular}{|c|c|c|c|c|c|c|}
\hline $\begin{array}{l}\text { double- } \\
\text { stranded } \\
\text { DNA }\end{array}$ & $\begin{array}{c}\Delta H^{\circ} \\
(\mathrm{kcal} / \mathrm{mol})^{b}\end{array}$ & $\begin{array}{c}\Delta S^{\circ} \\
(\mathrm{cal} / \mathrm{K} \cdot \mathrm{mol})^{c}\end{array}$ & $\begin{array}{l}\Delta G^{\circ}\left(25^{\circ} \mathrm{C}\right) \\
(\mathrm{kcal} / \mathrm{mol})^{d}\end{array}$ & $\begin{array}{l}\Delta G^{\circ}\left(50^{\circ} \mathrm{C}\right) \\
(\mathrm{kcal} / \mathrm{mol})^{d}\end{array}$ & $\begin{array}{c}T_{\mathrm{m}}\left(C_{\mathrm{T}}=100 \mu \mathrm{M}\right) \\
\left({ }^{\circ} \mathrm{C}\right)_{\mathrm{e}}\end{array}$ & buffer \\
\hline $\begin{array}{l}\mathrm{C} \cdot \mathrm{C} \\
\mathrm{M}_{\mathrm{Fu}}-\mathrm{C} \cdot \mathrm{M}_{\mathrm{Fu}}-\mathrm{C} \\
\mathrm{A} \cdot \mathrm{B} \\
\mathrm{M}_{\mathrm{Fu}}-\mathrm{A} \cdot \mathrm{B} \\
\mathrm{M}_{\mathrm{Py}}-\mathrm{A} \cdot \mathrm{B}\end{array}$ & $\begin{array}{l}-44.5 \\
-35.9 \\
-80.9 \\
-81.9 \\
-86.3\end{array}$ & $\begin{array}{r}-119 \\
-96 \\
-228 \\
-227 \\
-244\end{array}$ & $\begin{array}{r}-9.0 \\
-7.2 \\
-12.9 \\
-14.2 \\
-13.6\end{array}$ & $\begin{array}{l}-6.0 \\
-4.8 \\
-7.2 \\
-8.5 \\
-7.5\end{array}$ & $\begin{array}{l}51 \\
41 \\
51 \\
57 \\
53\end{array}$ & $\begin{array}{l}f \\
f \\
g \\
g \\
g\end{array}$ \\
\hline \multicolumn{7}{|c|}{ 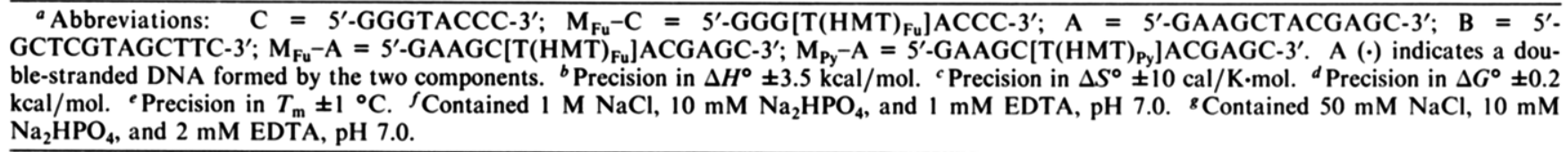 } \\
\hline
\end{tabular}

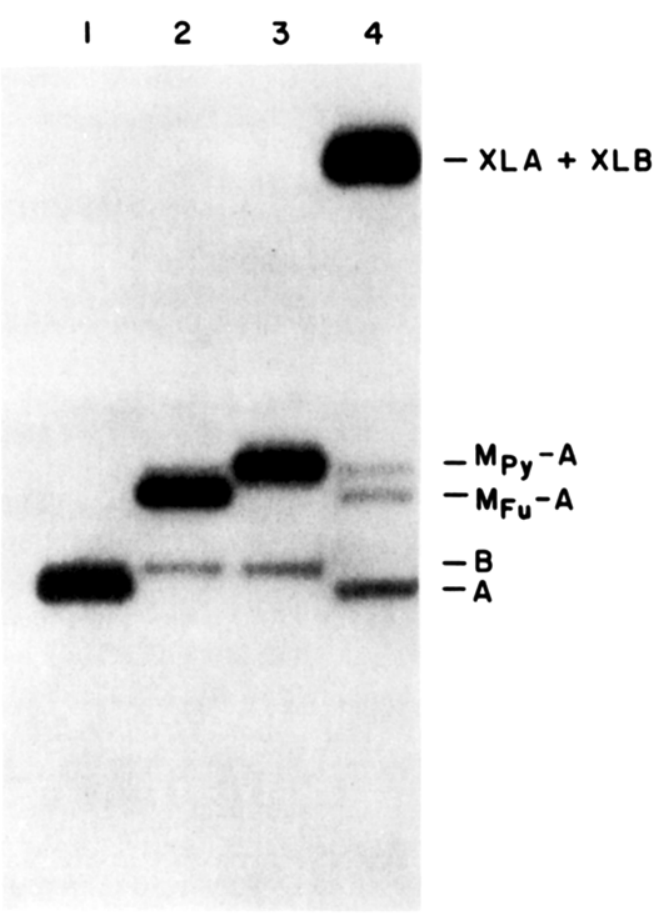

FIGURE 3: Analysis of oligonucleotides after melting curve measurements. Abbreviations: B, 5'-GCTCGTAGCTTC-3'; and as in Figure 2. (Lane 1) Mixture of oligonucleotides A and B after melting curve measurements; the ${ }^{32} \mathrm{P}$ specific activity of $A$ is about 6 times larger than that of $\mathbf{B}$. (Lane 2) Mixture of $\mathbf{B}$ and $\mathbf{M}_{\mathrm{Fu}}-\mathbf{A}$. (Lane 3) Mixture of $B$ and $M_{P y}-A$. (lane 4) A sample of the cross-links used to generate the $\mathrm{M}_{\mathrm{Fu}}-\mathrm{A}$ and $\mathrm{M}_{\mathrm{Py}}-\mathrm{A}$ after an exposure to 254-nm light from a low-pressure 40 -W germicidal lamp (3 min at a distance of about $6 \mathrm{~cm}$ ). The two cross-links were not resolved because of the partial kinasing of the complementary $8 \mathrm{mer}$ (see Materials and Methods)

AGCTACGAGC-3'. The psoralen was site specifically placed on the thymidine residue of oligonucleotide $5^{\prime}$-GAAGCTACGAGC-3'. The melting curves for the helix formed between 5'-GCTCGTAGCTTC-3' and 5'-GAAGC[T$\left.(\mathrm{HMT})_{\mathrm{Py}}\right]$ ACGAGC-3' $3^{\prime}$ are shown in Figure 1. Similar melting curves were obtained for the helices formed by $5^{\prime}$ GCTCGTAGCTTC-3' and 5'-GAAGCTACGAGC- $3^{\prime}$ or $5^{\prime}$-GAAGC[T(HMT) $\left.)_{\mathrm{Fu}}\right]$ ACGAGC-3'. The melting data were analyzed by the van't Hoff method. The van't Hoff plots for the helices with or without a psoralen are shown in Figure 4. The thermodynamic parameters thus obtained are listed in Table I. Two sets of free-energy values are shown in the table, one at $25^{\circ} \mathrm{C}$, which is the commonly used standard temperature, and one at $50^{\circ} \mathrm{C}$, which is close to the melting temperatures of the helices. Shown in Table II are the excess thermodynamic parameters due to the HMT additions, which are the differences between the thermodynamic parameters of the modified and unmodified helices. Results in Tables I

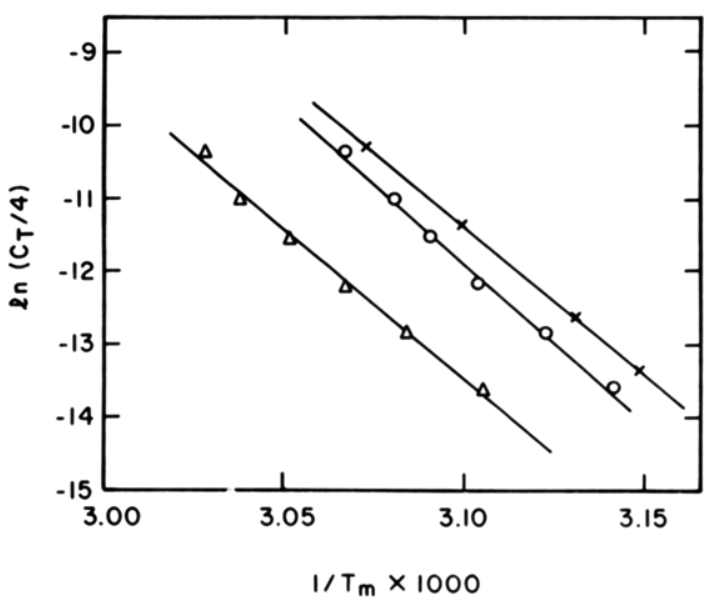

FIGURE 4: van't Hoff plots of $\ln \left(C_{\mathrm{T}} / 4\right)$ vs. $1 / T_{\mathrm{m}}$ for double-stranded helices formed by $(\Delta) \mathrm{B}+\mathrm{M}_{\mathrm{Fu}}-\mathrm{A},(\mathrm{O}) \mathrm{B}+\mathrm{M}_{\mathrm{Py}}-\mathrm{A}$, and $(X) \mathrm{B}+$ $A$ (see Figures 2 and 3 for abbreviations) in $50 \mathrm{mM} \mathrm{NaCl}, 10 \mathrm{mM}$ $\mathrm{Na}_{2} \mathrm{HPO}_{4}$, and $2 \mathrm{mM}$ EDTA, pH 7.0, where $C_{\mathrm{T}}$ is the total strand concentration (M) and $T_{\mathrm{m}}$ is the melting temperature (K).

$\begin{aligned} & \text { Table II: Excess Thermodynamic Parameters due to HMT } \\
& \text { Additions }{ }^{a}\end{aligned}$
\begin{tabular}{ccccc}
$\mathrm{HMT}$ & $\begin{array}{c}\Delta \Delta H^{\circ} \\
(\mathrm{kcal} / \mathrm{mol})\end{array}$ & $\begin{array}{c}\Delta \Delta S^{\circ} \\
(\mathrm{cal} / \mathrm{K} \cdot \mathrm{mol})\end{array}$ & $\begin{array}{c}\Delta \Delta G^{\circ}\left(25^{\circ} \mathrm{C}\right) \\
(\mathrm{kcal} / \mathrm{mol})\end{array}$ & $\begin{array}{c}\Delta \Delta G^{\circ}\left(50^{\circ} \mathrm{C}\right) \\
(\mathrm{kcal} / \mathrm{mol})\end{array}$ \\
$\begin{array}{c}\text { adducts in } \\
\mathrm{M}_{\mathrm{Fu}}-\mathrm{C} \cdot\end{array}$ & 8.6 & 23 & 1.8 & 1.2 \\
$\mathrm{M}_{\mathrm{Fu}}-\mathrm{C}$ & & & & \\
$\mathrm{M}_{\mathrm{Fu}}-\mathrm{A} \cdot \mathrm{B}$ & -1.0 & 1 & -1.3 & -1.3 \\
$\mathrm{M}_{\mathrm{Py}}-\mathrm{A} \cdot \mathrm{B}$ & -5.4 & -16 & -0.7 & -0.3 \\
\hline
\end{tabular}

\begin{tabular}{lccccc}
\hline${ }^{a}$ See Table I for abbreviations and buffer conditions. \\
\hline \multicolumn{6}{c}{ double-stranded DNA } \\
\hline Table III: & Hypochromicity of Double-Stranded DNA Helices ${ }^{a}$ \\
\hline \multicolumn{6}{c}{} \\
\cline { 2 - 6 } & C.C & $\begin{array}{l}\mathrm{M}_{\mathrm{Fu}}-\mathrm{C} \cdot \\
\mathrm{M}_{\mathrm{Fu}}-\mathrm{C}\end{array}$ & $\mathrm{A} \cdot \mathrm{B}$ & $\mathrm{M}_{\mathrm{Fu}}-\mathrm{A} \cdot \mathrm{B}$ & $\mathrm{M}_{\mathrm{Py}}-\mathrm{A} \cdot \mathrm{B}$ \\
\hline$\%\left(50^{\circ} \mathrm{C}\right)$ & 12.0 & 7.6 & 14.3 & 14.7 & 14.2
\end{tabular}

${ }^{a}$ See Table I for abbreviations and buffer conditions. Precision in $\%$ $H \pm 0.8$.

and II show that the HMT monoaddition does not destablize the double helix. Instead, it stabilizes the helices, especially in the case of furan-side monoaddition. The free energy of helix formation at $25^{\circ} \mathrm{C}$ is changed by $-1.3 \mathrm{kcal} / \mathrm{mol}$ for the furan-side monoaddition and by $-0.7 \mathrm{kcal} / \mathrm{mol}$ for the pyrone-side monoaddition. Due to the large experimental uncertainties in $\Delta H^{\circ}$ and $\Delta S^{\circ}$, it is difficult to separate the entropic and enthalpic contributions. It is likely that pyrone-side monoaddition of HMT slightly favors double-helix formation through a negative enthalpy contribution, which is $-5.4 \pm 7.0 \mathrm{kcal} / \mathrm{mol}$.

When double-stranded DNA is formed from complementary single-stranded DNAs, the stacking interactions between bases 


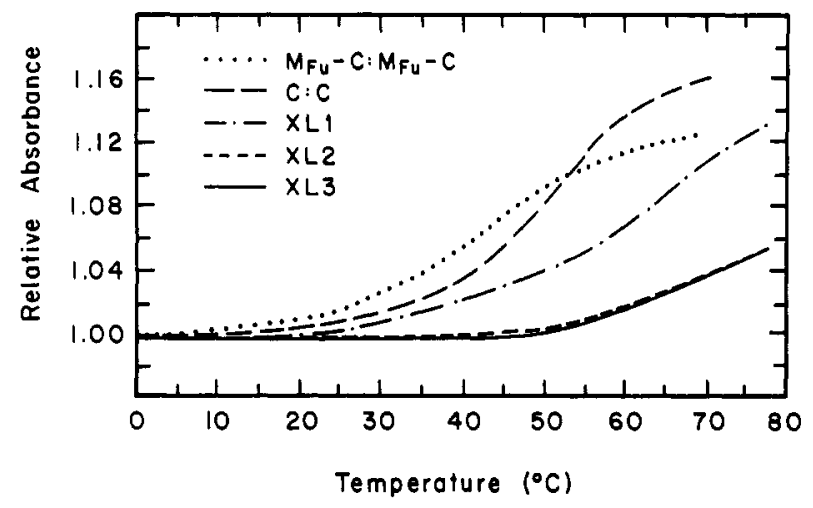

FIGURE 5: Melting curves of double helices formed by unmodified and HMT-modified oligonucleotide $5^{\prime}$-GGGTACCC-3' in $1 \mathrm{M} \mathrm{NaCl}$, $10 \mathrm{mM} \mathrm{Na}_{2} \mathrm{HPO}_{4}$, and $1 \mathrm{mM}$ EDTA, pH 7.0 (except XL1, see below). $\mathrm{M}_{\mathrm{Fu}}-\mathrm{C}$ and $\mathrm{C}$ are $5^{\prime}$-GGG[T(HMT) $\left.)_{\mathrm{Fu}}\right] \mathrm{ACCC}-3^{\prime}$ and $5^{\prime}-$ GGGTACCC-3', respectively. $\mathrm{M}_{\mathrm{Fu}} \cdot \mathrm{C}: \mathrm{M}_{\mathrm{Fu}}-\mathrm{C}$ and $\mathrm{C}: \mathrm{C}$ are the double-stranded DNA formed by these oligonucleotides. XL1, XL2, and XL3 are samples of HMT cross-linked $C: C$ at different concentrations. The total strand concentrations are $\left[\mathrm{M}_{\mathrm{Fu}}-\mathrm{C}\right)=100 \mu \mathrm{M},[\mathrm{C}]=77$ $\mu \mathrm{M},[\mathrm{XL2}]=20 \mu \mathrm{M},[\mathrm{XL} 3]=10 \mu \mathrm{M}$, and $[\mathrm{XL1}]=2 \mu \mathrm{M}$ in $1 \mathrm{mM}$ Tris- $\mathrm{HCl}, 0.1 \mathrm{mM}$ EDTA, and ca. $2 \mathrm{mM} \mathrm{NaCl}, \mathrm{pH}$ 7.5. The absorptions were normalized at $0^{\circ} \mathrm{C}$.

increase, and consequently, the absorption at $260 \mathrm{~nm}$ decreases. this is known as the hypochromicity of double-stranded DNA formation. The hypochromicities shown in Table III for the unmodified and the HMT-monoadducted double helices described above at $260 \mathrm{~nm}$ and $50^{\circ} \mathrm{C}$ are the same within experimental error. This indicates that stacking interactions between base pairs are only very slightly, if at all, perturbed. It also suggests that the psoralen moiety is stacked with adjacent base pairs. These conclusions are confirmed by the $\Delta H^{\circ}$ of the formation of the monoadducted helices, which are about the same as or slightly more negative than that of the unmodified helix, since stacking interactions are the dominant contributor to $\Delta H^{\circ}$.

Thermostability of Double-Stranded DNA Formed by Unmodified or HMT-Modified 5'-GGGTACCC-3'. The self-complementary oligonucleotide $5^{\prime}-\mathrm{GGG}\left[\mathrm{T}(\mathrm{HMT})_{\mathrm{Fu}}\right]$ ACCC- $3^{\prime}$ is still capable of forming a double-stranded helix despite the presence of the two psoralen monoadducts on the adjacent $\mathrm{A}-\mathrm{T}$ base pairs. If both of the psoralen groups were intercalated between the same adjacent base pairs in the helix, the helix would have to be extended by about $6.8 \AA$, about twice the extension when only one psoralen is intercalated (Kao, 1984). This is unlikely; therefore, we conclude that one of the psoralens and the thymidine to which it is attached must be bulged out of the helix. The thermostability of this deformed helix should be different from that of the unmodified helix. Data in Figure 5 show that this is the case. The melting curve shifts toward lower temperature and the hypochromicity is smaller for the helix formed by the furan-side monoadducted DNA as compared to the unmodified helix. The melting curves of the unmodified and HMT-modified helices were analyzed by the van't Hoff method. The van't Hoff plots from these melting curves are shown in Figure 6 and the thermodynamic parameters thus derived in Table I. The melting point of the HMT-monoadducted helix is about $10^{\circ} \mathrm{C}$ lower than that of the unmodified helix at a total strand concentration of $100 \mu \mathrm{M}$. The HMT additions increase the free energy of double-helix formation by $1.8 \mathrm{kcal} / \mathrm{mol}$ at $25^{\circ} \mathrm{C}$ in $1 \mathrm{M} \mathrm{NaCl}$. From the excess thermodynamic parameters in Table II, it can be seen that the destabilization originates from the unfavorable $\Delta H^{\circ}$, which is increased by $8.6 \mathrm{kcal} / \mathrm{mol}$. This suggests a perturbation in the stacking interaction between the base pairs, probably near the thymidine bulged outside of the helix. This

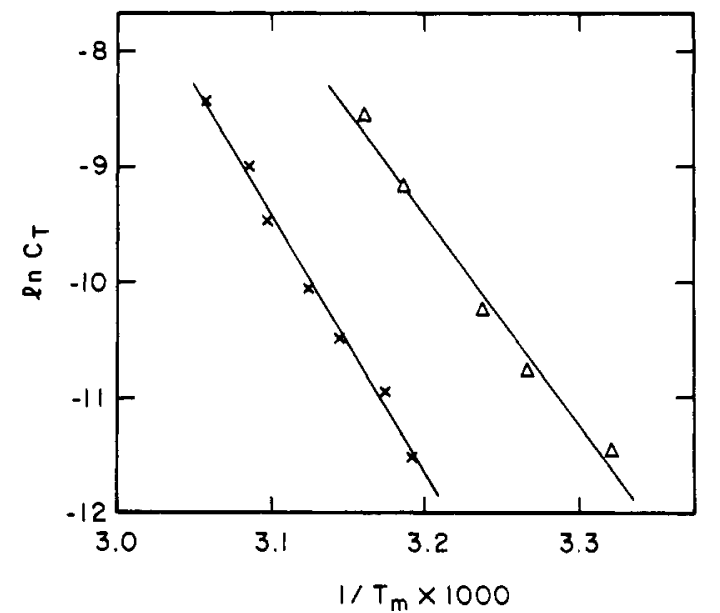

FIGURE 6: van't Hoff plots of $\ln C_{\mathrm{T}}$ vs. $1 / T_{\mathrm{m}}$ for double-stranded helices formed by $(\Delta) 5^{\prime}-\mathrm{GGG}\left[\mathrm{T}(\mathrm{HMT})\right.$ Fu $_{\mathrm{mu}} \mathrm{ACCC}-3^{\prime}$ and $(\times) 5^{\prime}$ GGGTACCC- $3^{\prime}$ in $1 \mathrm{M} \mathrm{NaCl}, 10 \mathrm{mM} \mathrm{Na}_{2} \mathrm{HPO}_{4}$, and $1 \mathrm{mM}$ EDTA, $\mathrm{pH} 7.0$, where $C_{\mathrm{T}}$ is the total strand concentration (M) and $T_{\mathrm{m}}$ is the melting temperature $(\mathrm{K})$.

is also supported by a positive increase in $\Delta S^{\circ}$, which is 23 $\mathrm{cal} / \mathrm{K} \cdot \mathrm{mol}$, and a decrease in hypochromicity upon the monoaddition of two HMT molecules (see Tables II and III).

When the two strands of the double helix formed by $5^{\prime}$ GGGTACCC- $3^{\prime}$ are cross-linked together by an HMT molecule via the thymidine base on each strand, the helix is remarkably stabilized. As shown in Figure 5, the melting of the cross-linked double helix is independent of concentration as expected for a unimolecular process. The cross-linked helix is so stable that it is essentially double stranded in $1 \mathrm{M} \mathrm{NaCl}$ at $51{ }^{\circ} \mathrm{C}$, which is the melting temperature of the unmodified helix at a total strand concentration of $100 \mu \mathrm{M}$. In a buffer containing only $2 \mathrm{mM} \mathrm{NaCl}, 1 \mathrm{mM}$ Tris- $\mathrm{HCl}$, and $0.1 \mathrm{mM}$ EDTA, at $\mathrm{pH} 7.5$, the melting is broad and the DNA is double-stranded at room temperature. This high stability of a cross-linked double-stranded DNA and the unimolecular nature of the single-stranded to double-stranded DNA transition made possible the kinetic studies of psoralen-DNA photochemistry by Johnston et al. $(1977,1981)$.

\section{Discussion}

The thermodynamic data for the unmodified and HMTmodified double helices formed between oligonucleotide 5'GAAGCTACGAGC- $3^{\prime}$ and its complement $5^{\prime}$ GCTCGTAGCTTC-3' demonstrate that HMT monoaddition to the thymidine residue in 5'-GAAGCTACGAGC-3' stabilizes the helix by 0.7 and $1.3 \mathrm{kcal} / \mathrm{mol}$ at $25^{\circ} \mathrm{C}$ in $50 \mathrm{mM}$ $\mathrm{NaCl}$ for pyrone-side and furan-side monoaddition, respectively. X-ray crystallographic study has shown that in the monoadduct formed between thymine and 8-methoxypsoralen the thymine and psoralen moieties remain planar and the interplanar angle is about $50^{\circ}$ (Peckler et al., 1982). The hypochromicity and enthalpy results reported here indicate that the stacking interactions between the psoralen and adjacent bases are strong enough to compensate for the possible distortions caused by HMT photoaddition. Though the results cannot definitely determine whether the stabilizing effect of psoralen monoaddition on the double helix is enthalpic or entropic, the excess thermodynamic values of $\Delta H^{\circ}$ and $\Delta S^{\circ}$ due to pyrone-side monoaddition (Table II) suggest that change in $\Delta H^{\circ}$ may be the dominant factor. Our results do not address whether or not these effects are dependent on the DNA sequence around the psoralen.

Double-stranded DNA melting is known to be dependent 
on counterion concentration because different amounts of counterions associate with double-stranded and single-stranded DNA. Covalent addition of a psoralen molecule to a DNA helix results in an increase in the separation between phosphates around the psoralen, especially in a double-stranded helix. The negative charge density is altered, and the counterion condensation is consequently changed. In order to determine the effect of psoralen monoaddition on the salt dependence of double-stranded DNA stability, the $\mathrm{NaCl}$ concentration of the buffer used in the melting curve measurements was increased from $50 \mathrm{mM}$ to $1 \mathrm{M}$ without altering other components of the buffer. The melting temperatures of both the unmodified helix and the two HMT-monoadducted double helices were increased by about $11^{\circ} \mathrm{C}$ at a total strand concentration of $10 \mu \mathrm{M}$. No difference was observed within experimental error (data not shown).

The thermodynamic parameters of double-stranded helix formation by the unmodified or the HMT-monoadducted self-complementary oligonucleotide $5^{\prime}$-GGGTACCC- $3^{\prime} \mathrm{dem}$ onstrate that upon covalent addition of a HMT molecule to each of the two thymidine bases in the double helix as a furan-side monoadduct, stacking interactions are dramatically reduced as reflected in the decreased hypochromicity and the excess thermodynamic parameters (Tables III and II). Since it is impossible for the two HMT moieties to be accommodated between the same two A-T base pairs, this destabilizing effect may be caused by forcing one of the thymidines and its attached psoralen out of the helix. This thymidine and its attached psoralen moiety could be moved out of the helix by rotating the $\mathrm{P}-\mathrm{O}$ bonds around the thymidine residue. Morden et al. (1983) have reported that the unpaired cytosine in the DNA helix formed by $5^{\prime}-\mathrm{CA}_{3} \mathrm{CA}_{3} \mathrm{G}-3^{\prime}$ and $5^{\prime}-\mathrm{CT}_{6} \mathrm{G}-3^{\prime}$ is outside of the helix, and this extrahelical cytosine causes a 15 ${ }^{\circ} \mathrm{C}$ decrease in the helix melting temperature and a positive increase in $\Delta G^{\circ}$ of helix formation at $25^{\circ} \mathrm{C}$ of $2.9 \mathrm{kcal} / \mathrm{mol}$ in $1 \mathrm{M} \mathrm{NaCl}$ buffer at a total strand concentration of $200 \mu \mathrm{M}$. This destabilizing effect is the result of an unfavorable change in enthalpy and a possibly favorable change in entropy. Their proton NMR results indicate that there is a change in the stacking interactions between adjacent bases around the extrahelical cytosine. In the case of the double-stranded DNA formed by $5^{\prime}$-GGG $[\text { T(HMT) })_{\mathrm{Fu}}$ ]ACCC-3', the free energy of helix formation is changed by $1.8 \mathrm{kcal} / \mathrm{mol}$ at $25^{\circ} \mathrm{C}$, and the melting point is decreased by $10^{\circ} \mathrm{C}$ at a total strand concentration of $100 \mu \mathrm{M}$ as compared to the unmodified helix. The addition of the psoralen molecules is associated with an unfavorable enthalpy change and a favorable entropy change for the helix formation. The monoaddition of a HMT molecule as a furan-side monoadduct in the double helix formed by oligonucleotides $5^{\prime}$-GAAGCTACGAGC-3' and $5^{\prime}$. GCTCGTAGCTTC-3' decreases the $\Delta G^{\circ}$ of the helix formation by $1.3 \mathrm{kcal} / \mathrm{mol}$ at $25^{\circ} \mathrm{C}$ and increases the melting temperature by about $6^{\circ} \mathrm{C}$ in $50 \mathrm{mM} \mathrm{NaCl}$ (see Tables I and II). The effects due to the exclusion of one of the two HMT-thymidine groups from the helix formed by $5^{\prime}$-GGG$\left[\mathrm{T}(\mathrm{HMT})_{\mathrm{Fu}}\right] \mathrm{ACCC}-3^{\prime}$ are similar to the effects of the extrahelial cytosine if one assumes that the other HMT-thymidine group remains inside the helix, and stabilizes the helix to about the same extent as in the case where only one psoralen is attached to the helix as a furan-side monoadduct.

Adenosine is the base with strongest stacking tendency (Morden et al., 1983); it prefers to stack inside the helix even if it cannot form a base pair. Patel et al. (1982) have reported that the extra adenosines stack into the helix formed by the nearly self-complementary deoxyoligonucleotide $5^{\prime}$-CGCa-
GAATTCGCG-3'. In the double helix formed by $5^{\prime}$-GGG$\left[\mathrm{T}(\mathrm{HMT})_{\mathrm{Fu}}\right] \mathrm{ACCC}-3^{\prime}$, the adenosine opposite the HMTthymidine that is outside the helix would be expected to remain inside the helix, though it cannot form hydrogen bonds with that thymidine. The other adenosine may be base paired as usual with the HMT-thymidine group opposing it, and the psoralen moiety is probably stacked onto the base pair.

The fact that psoralen monoaddition does not destabilize the double-stranded DNA helix suggests that psoralen monoaddition can be very useful in nucleic acid secondary and tertiary structure determination. Psoralens have been widely used as nucleic acid structure probes (Cimino et al., 1985). Traditionally, single-stranded nucleic acids are irradiated in the presence of psoralens with light of $320-400 \mathrm{~nm}$ in order to determine possible secondary or even tertiary structures. Double-stranded regions in these nucleic acids are thus cross-linked by psoralen molecules. The cross-linked regions can then be analyzed by the method described by Thompson and Hearst (1983). In these kinds of experiments, all the double-stranded regions can be cross-linked by psoralen molecules. This makes the product analysis very difficult. In contrast, the product analysis can be enormously simplified if one uses a psoralen-transfer technology. As described by Cimino et al. (1986), this method allows one to place a psoralen molecule site specifically in a nucleic acid as either a furan-side monoadduct or a pyrone-side monoadduct. Subsequent reconstitution will allow secondary and tertiary structures to re-form. Because the stability of monoadducted double helices is similar to that of the unmodified helices, the secondary and tertiary structures re-formed should be very close to the structures of the unmodified nucleic acid, and they can be determined by irradiating the reconstituted nucleic acid to cross-link possible double-stranded region(s) containing the psoralen monoadduct. The analysis of the cross-links should be easy since the sequence of the site to which the psoralen was initially transferred is known. The degree of stabilization of psoralen monoaddition on double-stranded nucleic acids should be dependent on the substitutions on psoralen molecules, since it is known that different psoralen derivatives have different binding constants to nucleic acids (Isaacs et al., 1977, 1982). Different psoralen derivatives can be used in structure determination if one needs to minimize the stabilization effect.

\section{CONCLUSIONS}

We have shown that monoaddition of the psoralen derivative HMT to a thymidine residue in double-stranded DNA as either a furan-side monoadduct or a pyrone-side monoadduct slightly stabilizes the helix. The stacking interactions between base pairs are only very slightly, if at all, perturbed, and the psoralen moiety is probably stacked with adjacent base pairs. A self-complementary oligonucleotide containing a HMTthymidine furan-side monoadduct is still capable of forming a double-stranded helix. The double-stranded helix thus formed is, however, dramatically destabilized compared to the unmodified helix. Presumably, one psoralen moiety together with its attached thymidine is forced out of the helix, and the other is stacked inside.

\section{ACKNOWLEDGMENTS}

We thank Professor Tinoco for the use of the melting curve measurement apparatus. We express our deep appreciation to F. Aboul-ela for his help with the melting curve experiments and for many helpful discussions and to M. Ferguson for the synthesis of the oligonucleotides. We also thank Dr. H. Gamper, Dr. G. D. Cimino, J. D. Kahn, and other colleagues 
for helpful discussions and critical comments on the manuscript.

\section{REFERENCES}

Aboul-ela, F., Koh, D., Tinoco, I., Jr., \& Martin, F. H. (1985) Nucleic Acids Res. 13, 4811-4824.

Baba, Y., Beatty, C. L., \& Kagemoto, A. (1981) Org. Coat. Plast. Chem. 44, 223-227.

Borer, P. N., Dengler, B., Tinoco, I., Jr., \& Uhlenbeck, O. C. (1974) J. Mol. Biol. 86, 843-853.

Cimino, G. D., Gamper, H. B., Isaacs, S. T., \& Hearst, J. E. (1985) Annu. Rev. Biochem. 54, 1151-1193.

Cimino, G. D., Shi, Y.-B., \& Hearst, J. E. (1986) Biochemistry 25, 3013-3020.

Craig, M. E., Crothers, D. M., \& Doty, P. (1971) J. Mol. Biol. 62, 383-401.

Fasman, G. D. (1975) Biochem., Mol. Biol., 3rd Ed. 1, 589.

Fitzpatrick, J. B., Stern, R. S., \& Parrish, J. A. (1982) in Psoriasis, Proceedings of the International Symposium, $3 \mathrm{rd}$ (Farber, E. M., Ed.) pp 149-156, Grune and Straton, New York.

Gamper, H., Piette, J., \& Hearst, J. E. (1984) Photochem. Photobiol. 40, 29-34.

Isaacs, S. T., Shen, C.-K. J., Hearst, J. E., \& Rapoport, H. (1977) Biochemistry 16, 1058-1064.

Isaacs, S. T., Chun, C., Hyde, J, E., Rapoport, H., \& Hearst, J. E. (1982) in Trends in Photobiology (Helene, C., Charlier, M., Monternay-Carestier, T., \& Laustriat, G., Eds.) pp 279-294, Plenum, New York.

Johnston, B. H., Johnson, M. A., Moore, C. B., \& Hearst, J. E. (1977) Science (Washington, D.C.) 197, 906-908.

Johnston, B. H., Kung, A. H., Moore, C. B., \& Hearst, J. E. (1981) Biochemistry 20, 735-738.
Kanne, D. Straub, K., Hearst, J. E., \& Rapoport, H. (1982a) J. Am. Chem. Soc. 104, 6754-6764.

Kanne, D., Straub, K., Rapoport, H., \& Hearst, J. E. (1982b) Biochemistry 21, 861-871.

Kao, J. P.-Y. (1984) Ph.D. Thesis, University of California.

Maniatis, T., Fritsch, E. F., \& Sambrook, J. (1982) in Molecular Cloning, pp 125-126, Cold Spring Harbor Laboratory, Cold Spring Harbor, NY.

Martin, F. H., Uhlenbeck, O. C., \& Doty, P. (1971) J. Mol. Biol. 57, 201-215.

Morden, K. M., Chu, Y. C., Martin, F. H., \& Tinoco, I., Jr. (1983) Biochemistry 22, 5557-5563.

Nelson, J. W., \& Tinoco, I., Jr. (1984) Biopolymers 23, 213-233.

Parrish, J. A., Stern, R. S., Pathak, M. A., \& Fitzpatrick, J. B. (1982) in Science of Photomedicine (Regan, J. D., \& Parrish, J. A., Eds.) pp 595-623, Plenum, New York.

Parsons, B. J. (1980) Photochem. Photobiol. 32, 813-821.

Patel, D. J., Kozlowski, S. A., Marky, L. A., Rice, J. A., Broka, C., Itakura, K., \& Breslauer, K. J. (1982) Biochemistry 21, 445-451.

Peckler, S., Graves, B., Kanne, D., Rapoport, H., Hearst, J. E., \& Kim, S.-H. (1982) J. Mol. Biol. 162, 157-172.

Porschke, P., \& Eigen, M. (1971) J. Mol. Biol. 62, 361-381.

Riesner, D., \& Romer, R. (1973) in Physico-Chemical Properties of Nucleic Acids (Duchesne, J., Ed.) Vol. 2, pp 237-318, Academic, London.

Song, P. S., \& Tapley, K. J., Jr. (1979) Photochem. Photobiol. 29, 1177-1197.

Straub, K., Kanne, D., Hearst, J. E., \& Rapoport, H. (1982) J. Am. Chem. Soc. 103, 2347-2355.

Thompson, J. F., \& Hearst, J. E. (1983) Cell (Cambridge, Mass.) 32, 1355-1365.

\title{
NMR Studies of the Complex between the Decadeoxynucleotide d-(GCATTAATGC) ${ }_{2}$ and a Minor-Groove-Binding Drug ${ }^{\dagger}$
}

\author{
Werner Leupin, ${ }^{*}$ Walter J. Chazin, ${ }^{\ddagger}$ Sven Hyberts, William A. Denny, ${ }^{\S}$ and Kurt Wüthrich \\ Institut für Molekularbiologie und Biophysik, ETH-Hönggerberg, CH-8093 Zürich, Switzerland
}

Received March 21, 1986; Revised Manuscript Received June 3, 1986

\begin{abstract}
Nearly all ${ }^{1} \mathrm{H}$ NMR lines of the complex formed between the bis(quaternary ammonium) heterocycle 4-[p-[p-(4-quinolylamino)benzamido]anilino]pyridine (1, also known as SN 6999) and the decadeoxyribonucleoside nonaphosphate d-(GCATTAATGC) ${ }_{2}$ were sequentially assigned by using oneand two-dimensional NMR techniques. Intermolecular nuclear Overhauser effects between the ligand and the DNA show that the drug binds in the minor groove of the DNA, interacting with the central A-T base pairs. Over the temperature range from 277 to $313 \mathrm{~K}$, the lifetime of the drug in the DNA binding sites is short relative to the NMR time scale, since fast exchange is observed for all but a few protons. A model for the binding of 1 to d-(GCATTAATGC $)_{2}$ is proposed, where the drug binds to two equivalent sites covering approximately five A-T base pairs, which assumes exchange of 1 between these two binding sites.
\end{abstract}

I In the search of guidelines for the development of new drugs that are biologically active through binding to DNA, there has

\footnotetext{
${ }^{+}$This work was supported by the Swiss National Science Foundation (Project 3.284.82), the Auckland Division of the Cancer Society of New Zealand, and the Medical Research Council of New Zealand, through an ICRETT grant (to W.A.D.) and through a postdoctoral fellowship (to W.J.C.) from Les Fonds FCAC du Québec.

${ }^{\ddagger}$ Present address: Department of Molecular Biology, Scripps Clinic and Research Foundation, La Jolla, CA 92037.

\$ Permanent address: Cancer Research Laboratory, University of Auckland School of Medicine, Auckland, New Zealand.
}

been a growing interest in the examination of drug-DNA complexes, both in the crystalline state and in solution. DNA-drug complexes may furthermore also serve as models for the study of gene expression and its control by interactions between DNA and proteins. Most NMR studies in this field so far focused on DNA complexes with various intercalating agents [e.g., Reid et al. (1983a), Assa-Munt et al. (1985), Patel et al. (1981), and Lown and Hanstock (1985)]. One minorgroove-binding drug was also studied in detail, i.e. netropsin [see Patel (1982) and Patel and Shapiro (1985) and references 